\title{
Inequity in colorectal cancer treatment and outcomes: a population-based study
}

\author{
A-E Carsin', L Sharp*,', DP Cronin-Fenton², A Ó Céilleachair' and H Comber' \\ 'National Cancer Registry, Ireland, Building 6800, Cork Airport Business Park, Kinsale Road, Cork, Ireland; '² Department of Clinical Epidemiology, Aarhus \\ University Hospital, Ole Worms Alle 1150, Aarhus C 8000, Denmark
}

\begin{abstract}
Several uncertainties surround optimal management of colorectal cancer. We investigated treatment patterns and factors influencing treatment receipt and mortality in routine clinical practice. We included 15249 individuals, recorded by the National Cancer Registry (Ireland), with primary invasive colon or rectal tumours, diagnosed during 1994-2002. Logistic regression and Cox proportional hazards were used to determine factors associated with treatment receipt within I year of diagnosis and with mortality, respectively. A total of $78 \%$ had colorectal resection, $31 \%$ chemotherapy, and I 3\% radiotherapy (4\% colon; $28 \%$ rectum). Half of stage IV patients underwent resection. Chemotherapy and radiotherapy use increased by at least $10 \%$ per annum. There was a notable increase in pre-operative radiotherapy from 2000 onwards. Patient-related factors were significantly associated with treatment receipt. Patients who were male, older, not married, or smokers had significantly higher risks of death. Chemotherapy was significantly associated with lower mortality for stage III, but not stage II, colon cancer. For rectal cancer, pre-operative radiotherapy was associated with reduced mortality. Surgery and chemotherapy were associated with longer survival for stage IV patients. The observed inequities in treatment and outcomes suggest that there is potential for further dissemination of therapies in routine practice. Improving treatment availability overall, and equity, has the potential to reduce mortality.
\end{abstract}

British Journal of Cancer (2008) 99, 266-274. doi:I0.I038/sj.bjc.6604467 www.bjcancer.com

Published online I July 2008

(c) 2008 Cancer Research UK

Keywords: colorectal cancer; resection; chemotherapy; radiotherapy; survival

Colorectal cancer is responsible for more than half a million deaths worldwide each year (Ferlay et al, 2004). In many developed countries, mortality rates have been falling for 20-30 years (Coleman et al, 1993), reflecting steady improvements in survival (Verdecchia et al, 2007). However, there remains considerable international variation in survival even between developed nations; 5 -year relative survival for patients in the USA is around $65 \%$, whereas that within Europe ranges between 45 and $64 \%$ (Verdecchia et al, 2007). Differences in stage at diagnosis, although important (Gatta et al, 2000; Ciccolallo et al, 2005), do not completely explain survival inequalities. Variations in treatment use and quality may also play a role.

Several uncertainties surround optimal colorectal cancer therapy, and this is reflected in variations in best-practice guidelines. Although surgery is the cornerstone of treatment for apparently localized disease, international variations have been reported in resection rates (Ciccolallo et al, 2005). For locally advanced or metastatic disease, there is no consensus on when excision of the primary tumour should be attempted (SIGN, 2003; NCCN, 2006a, b). Use of adjuvant therapy depends both on site and stage. For example, adjuvant chemotherapy is not routinely recommended for stage II colon cancer (SIGN, 2003; Australian Cancer Network Colorectal Cancer Guidelines Revision Committee,

*Correspondence: Dr L Sharp; E-mail: linda.sharp@ncri.ie Revised I May 2008; accepted 27 May 2008; published online I July 2008
2005) given the inconclusive findings from randomised controlled trials (RCTs) (Mamounas et al, 1999; Benson et al, 2004). However, some recent studies suggest that stage II patients with poor prognostic features (such as bowel perforation, involved lymph nodes, etc.) might benefit (Gill et al, 2004; André et al, 2006) and US and Australian guidelines advocate chemotherapy for this subgroup (Australian Cancer Network Colorectal Cancer Guidelines Revision Committee, 2005; NCCN, 2006a). For stage III colon cancer, RCTs suggest that best practice is surgery followed by chemotherapy (5-fluorouracil (5-FU) -leucovorin or capecitabine, and more recently supplementation with oxaliplatin) to improve survival (Cascinu et al, 2003; André et al, 2004a; Twelves et al, 2005). In advanced disease, irinotecan or oxaliplatin with 5-FU is recommended for primary therapy (NICE, 2005). For rectal cancer, until recently post-operative radiotherapy was the standard of care for locally advanced disease, but RCTs have indicated that pre-operative administration may improve local control, with lower toxicity and reduced rectal cancer deaths (Colorectal Cancer Collaborative Group, 2001; Sauer et al, 2004). The addition of chemotherapy improves response and is recommended (SIGN, 2003; Australian Cancer Network Colorectal Cancer Guidelines Revision Committee, 2005).

How these uncertainties and complexities translate into routine clinical practice is not clear. Some studies have suggested that (neo-) adjuvant therapies may be under-utilized and that use depends on patient characteristics such as age or ethnicity (Schrag et al, 2001a, b; Potosky et al, 2002; Martijn et al, 2003; Cronin et al, 
2006). However, most population-based studies originate from the United States, relate to patients diagnosed in the first half of the 1990s, and/or focus on patient subgroups (e.g. stage III disease). We therefore undertook a population-based investigation of trends in treatment and factors predicting treatment receipt, survival, and mortality for patients with all stages of disease during 1994-2002 in Ireland - a country with relatively high colorectal cancer mortality (Ferlay et al, 2004).

\section{MATERIALS AND METHODS}

Details of individuals aged $\geqslant 20$ with invasive colorectal cancer (ICD-02: C18-20) diagnosed during 1994-2002 were abstracted from the National Cancer Registry (NCR), which records all cancers diagnosed in Ireland (www.ncri.ie). Completeness of registration is approximately $98 \%$ (NCR, 2001). Cases were excluded where diagnosis was made by death certificate only or at autopsy, or the tumour was a secondary malignancy (other than non-melanoma skin), or occurred simultaneously with another tumour.

Using information on treatments administered within 1 year of diagnosis, cases were categorised by receipt of (1) 'cancer-directed' surgery (i.e. colon or rectal resection), (2) chemotherapy, or (3) radiotherapy. Chemotherapy and radiotherapy were classified as 'any', 'pre-operative', or 'post-operative' based on dates of surgery and the start of the first treatment course. Stage was defined by AJCC summary staging (AJCC, 2002), making the assumption that patients with no information on distant metastasis (MX) had no metastasis (M0). Dates and causes of death were ascertained by linkage to death certificates. Patients were followed up from date of diagnosis to death or 31 December 2004, whichever was sooner.

Associations between patient characteristics and stage were evaluated using $\chi^{2}$ tests. Temporal trends in treatment were explored by jointpoint regression (Edwards et al, 2005). Multivariate logistic regression models, stratified by stage, were built to identify factors associated with treatment receipt. For surgery, only stage IV and unstaged patients were modelled, as almost all stage I-III patients had resection. For chemotherapy and radiotherapy, stage I patients were excluded as few received these therapies. Models were adjusted for sex and factors significant $(P<0.10)$ on likelihood ratio tests. Factors considered for inclusion were age, marital status, site, grade, tumour extent $(\mathrm{T})$, regional lymph node status $(\mathrm{N})$ (as within a given stage, subgroups of patients might receive adjuvant therapy), year of diagnosis, smoking status at diagnosis, and health board of residence (as cancer services were organised at this level in 1994-2002). Model goodness of fit was assessed by the Hosmer-Lemeshow test. Multivariate Cox proportional hazard models were run for all-cause and colorectal cancer-specific mortality. As results were similar, only all-cause mortality is presented. Surgical and non-surgical patients were modelled separately and covariates included if significant $(P<0.10)$ on Wald F-tests. Owing to non-proportional hazards, chemotherapy and radiotherapy were included as time-varying covariates with date of the start of the first course as the index date. In all models we tested for interactions between variables; any that were meaningful, statistically significant, and impacted on risk estimates were included in the final models. Kaplan-Meier curves, adjusted for age, were constructed to illustrate the impact of treatment on survival time.

\section{RESULTS}

Colon cancer accounted for $63 \%$ of the 15249 patients included. Overall, $57 \%$ were male (53\% of colon, $64 \%$ of rectal tumours) and $92 \%$ had histologically verified disease. Less than $12 \%$ were stage I, $25 \%$ were stage II, $23 \%$ were stage III, $22 \%$ were stage IV, and $17 \%$ were unknown stage. Unstaged patients were older and more often had rectal tumours. Stage distribution changed relatively little over time (stage I/II: $39 \%$ in $1994-96$ and $36 \%$ in $2000-02$; stage III/IV: 43 and $48 \%$; unstaged: 18 and $15 \%$ ).

\section{Treatment rates and trends over time}

Overall, $78 \%$ of patients had surgical resection, $31 \%$ chemotherapy, and $13 \%$ radiotherapy, the latter primarily for rectal cancer $(28 \%$ rectal, $4 \%$ colon; Table 1$)$. Almost all stage I-III patients (96\%) had surgery, compared with $51 \%$ with stage IV and $47 \%$ with unknown stage. Chemotherapy and radiotherapy were used almost exclusively among surgical patients. For rectal cancer, both therapies were more often used post-operatively (chemotherapy $31 \%$, radiotherapy $16 \%$ ) than pre-operatively (6 and $8 \%$, respectively). Overall, $17 \%$ of patients received no cancer-directed treatment; almost all of these had stage IV (45\%) or unstaged (47\%) disease.

From 1994 to 2002, there was no change in the proportion undergoing surgery (data not shown). Chemotherapy use increased significantly for both colon and rectal cancer (estimated annual percentage change $(\mathrm{EAPC})=+9.6 \%, 95 \%$ CI +8.4 , $+10.8 \%$; Figure 1A), although the increase slowed down for colon cancer patients in 2000-02. The growth in chemotherapy was evident for all disease stages. Use of radiotherapy for rectal cancer increased overall $(\mathrm{EAPC}=+12.3 \%, 95 \%$ CI $+10.3,+14.2 \%$; Figure 1B), particularly for those with stage I disease $(\mathrm{EAPC}=+23.0 \%, 95 \% \mathrm{CI}+16.0,+30.3 \%)$. The upward trend was most pronounced for pre-operative use $(\mathrm{EAPC}=+34.3 \%$, $95 \%$ CI $+24.7,+44.6 \%$; Figure $1 \mathrm{C}$ ), particularly from 2000 onwards.

\section{Factors associated with treatment receipt}

With regard to surgery for stage IV disease, in multivariate analyses, resection was significantly less common among patients who were older, unmarried, and male $(P \leqslant 0.01$; data not shown) and there was a borderline significant effect of site (multivariate odds ratio (OR) rectum $v$ s colon $=0.87,95 \%$ CI $0.75-1.01$ ). For

Table I Treatments administered to colorectal cancer patients diagnosed during 1994-2002: numbers and percentages of all patients

\begin{tabular}{|c|c|c|c|c|c|c|}
\hline \multirow[b]{2}{*}{ Variable } & \multicolumn{2}{|c|}{ Colon } & \multicolumn{2}{|c|}{ Rectum } & \multicolumn{2}{|c|}{ Total } \\
\hline & No. & $\%$ & No. & $\%$ & No. & $\%$ \\
\hline \multicolumn{7}{|l|}{ Overall treatment $t^{a}$} \\
\hline Surgery ${ }^{\mathrm{b}}$ & 7591 & 79.0 & 4285 & 76.0 & 11876 & 77.9 \\
\hline Any chemotherapy & 2807 & 29.2 & 1873 & 33.2 & 4680 & 30.7 \\
\hline Any radiotherapy & 410 & 4.3 & 1578 & 28.0 & 1988 & 13.0 \\
\hline \multicolumn{7}{|l|}{ Pre-operative treatment ${ }^{c}$} \\
\hline Chemotherapy & 45 & 0.6 & 240 & 5.6 & 285 & 2.4 \\
\hline Radiotherapy & 11 & 0.1 & 339 & 7.9 & 350 & 2.9 \\
\hline \multicolumn{7}{|l|}{ Postoperative treatment $^{c}$} \\
\hline Chemotherapy & 2435 & 31.9 & 1336 & 31.0 & 3771 & 31.6 \\
\hline Radiotherapy & 227 & 3.0 & 682 & 15.8 & 909 & 7.6 \\
\hline \multicolumn{7}{|l|}{ Treatment combinations } \\
\hline Surgery only ${ }^{\mathrm{b}}$ & 5000 & 52.0 & 2419 & 42.9 & 7419 & 48.7 \\
\hline Chemotherapy only & 304 & 3.2 & 123 & 2.2 & 427 & 2.8 \\
\hline Radiotherapy only & 41 & 0.4 & 174 & 3.1 & 215 & 1.4 \\
\hline Surgery and radiotherapy & 116 & 1.2 & 302 & 5.4 & 418 & 2.7 \\
\hline Surgery and chemotherapy & 2250 & 23.4 & 648 & 11.5 & 2898 & 19.0 \\
\hline Chemotherapy and radiotherapy & 28 & 0.3 & 186 & 3.3 & 214 & 1.4 \\
\hline $\begin{array}{l}\text { Surgery, radiotherapy, } \\
\text { and chemotherapy }\end{array}$ & 225 & 2.3 & 916 & 16.3 & 1141 & 7.5 \\
\hline No cancer-directed treatment & 1649 & 17.2 & 868 & 15.4 & 2517 & 16.5 \\
\hline
\end{tabular}

${ }^{\mathrm{a} C a t e g o r i e s ~ n o t ~ m u t u a l l y ~ e x c l u s i v e ; ~ f i g u r e s ~ d o ~ n o t ~ s u m ~ t o ~} 100 \%$. ${ }^{\mathrm{b}}$ Resection of the colon or rectum. 'Percentage of surgical patients. 


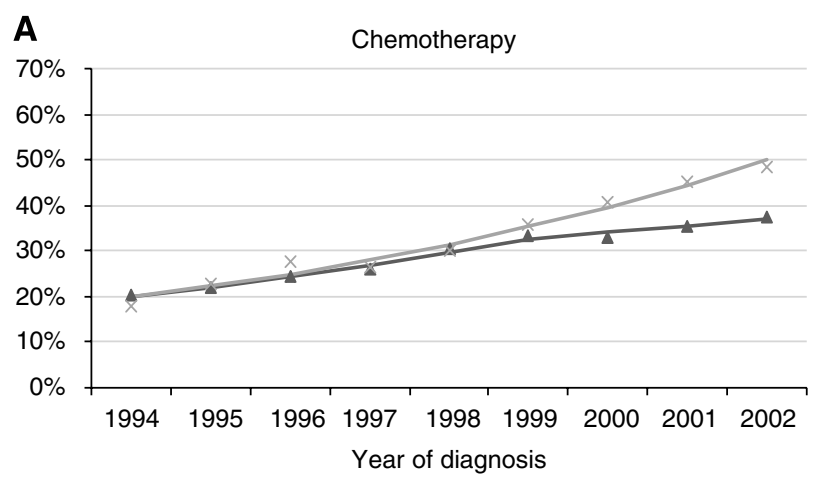

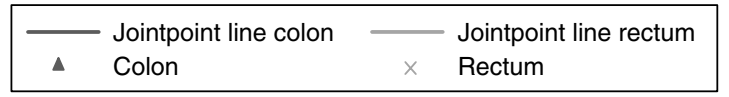
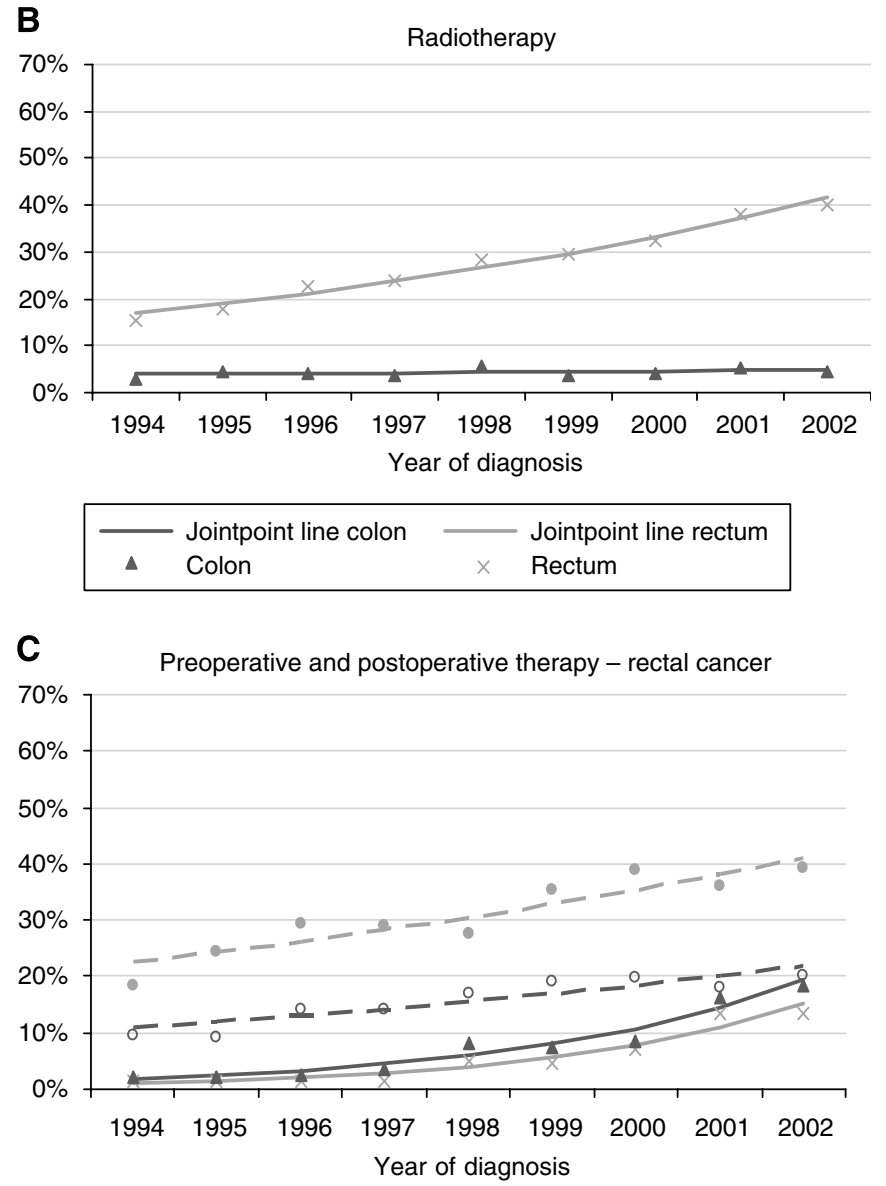

\begin{tabular}{|lll|}
\hline - Jointpoint line preop chemo & $\times$ & Preop chemotherapy \\
\hline Jointpoint line preop radio & $\wedge$ & Preop radiotherapy \\
- Jointpoint line postop chemo & $\bullet$ & Postop chemotherapy \\
- - Jointpoint line postop radio & $\circ$ & Postop radiotherapy \\
\hline
\end{tabular}

Figure I Trends in treatment receipt among colorectal cancer patients, 1994-2002: observed frequencies plus jointpoint regression lines. (A) chemotherapy (\% of all patients), (B) radiotherapy (\% of all patients), and (C) pre and postoperative therapy (\% of rectal cancers).

unknown stage disease, older, unmarried patients were significantly less likely to undergo resection $(P<0.001$; data not shown), as were those with tumour extent $\mathrm{T} 4(\mathrm{OR}=0.07,95 \%$ CI $0.05-0.11)$.

Table 2 shows factors associated with chemotherapy receipt. For all stages, older and unmarried patients were significantly less likely to receive chemotherapy. For stage III and IV patients, there was a strong positive effect of year of diagnosis. For stage II and unknown stage patients, there was year of diagnosis-site interaction; chemotherapy use increased over time, but to a greater extent for rectal than colon patients. Tumour extent was associated with likelihood of chemotherapy receipt. For stage II patients, those with $\mathrm{T} 4$ tumours were significantly more likely to be treated than those with T3 tumours (multivariate $\mathrm{OR}=1.69$, $95 \%$ CI 1.33-2.15). For III, IV, and unstaged patients, those with T3 tumours were most likely to have chemotherapy.

Table 3 shows factors associated with radiotherapy use in rectal cancer. For all disease stages, use decreased significantly with increasing age. Women were slightly less likely to get radiotherapy than men, and this was significant for stage II disease. For stage III patients, use was less common among those who were not married $(P=0.055)$. Tumour extent was significantly associated with radiotherapy receipt in patients with unknown and stage II disease, but not stage III and IV disease. Among those with stage II or unknown stage disease, patients with T4 tumours were more likely to receive radiotherapy than those with other tumours.

With regard to pre-operative radiotherapy specifically, use was significantly less frequent among female patients (multivariate $\mathrm{OR}=0.67,95 \%$ CI $0.51-0.87)$ and decreased with age ( $P($ trend) $<0.001$; data not shown).

\section{Survival and factors associated with mortality}

Five-year observed survival was $40 \%$ overall, and $72,59,41,7$, and $31 \%$ for stage I, II, III, IV, and unstaged tumours, respectively. It was $49 \%$ for surgical and $9 \%$ for non-surgical patients. Among stage IV patients, $50 \%$ who underwent resection were alive at 1 year compared with $16 \%$ who did not.

Table 4 shows factors associated with mortality, stratified by surgery receipt. The risk of death fell over time for surgical patients. In both groups, men had significantly higher hazard ratios (HR) than women, and married patients had lower hazards $(P \leqslant 0.01)$. The HR increased with age, particularly for older surgical patients. Patients who presented with later stage disease and with poorly differentiated or undifferentiated tumours had significantly higher hazards $(P \leqslant 0.01)$. Smokers had increased hazards, and this reached significance among surgical patients.

Table 5 shows HRs for chemotherapy and radiotherapy receipt, stratified by stage, and Figure 2 shows survival according to treatment. Stage III patients who received chemotherapy had a significantly reduced risk of death (all patients $\mathrm{HR}=0.67,95 \% \mathrm{CI}$ $0.61-0.75$ ) and higher survival (Figure 2A). No such effects were evident for stage II disease. For stage IV disease, surgical patients had higher survival; this was evident up to approximately 3 years after diagnosis among the group who had surgery and up to 2 years after diagnosis among those who did not have surgery (Figure 2B). Among surgical stage IV patients, chemotherapy receipt was associated with a significantly reduced risk of death $(\mathrm{HR}=0.77,95 \%$ CI $0.68-0.88)$. For rectal cancer, receipt of any radiotherapy (pre- or post-operative) had no significant impact on mortality for patients with any stage of disease (Table 5). However, when the analysis was limited to patients who had surgery and radiotherapy, those who received pre-operative, as compared with post-operative, radiotherapy had reduced HRs. This was seen for all stages of disease except stage II, but the reduction in the HR reached statistical significance only for stage III disease $(\mathrm{HR}=0.61,95 \%$ CI $0.42-0.91)$.

\section{DISCUSSION}

\section{Strengths and limitations}

This is one of the largest population-based studies of treatment trends and factors predicting treatment receipt for colorectal 
Table 2 Factors associated with chemotherapy receipt among colorectal cancer patients diagnosed during 1994-2002: observed and adjusted percentages, multivariate $\mathrm{ORs}^{\mathrm{a}}$ with $95 \% \mathrm{Cls}$, and $P$-values

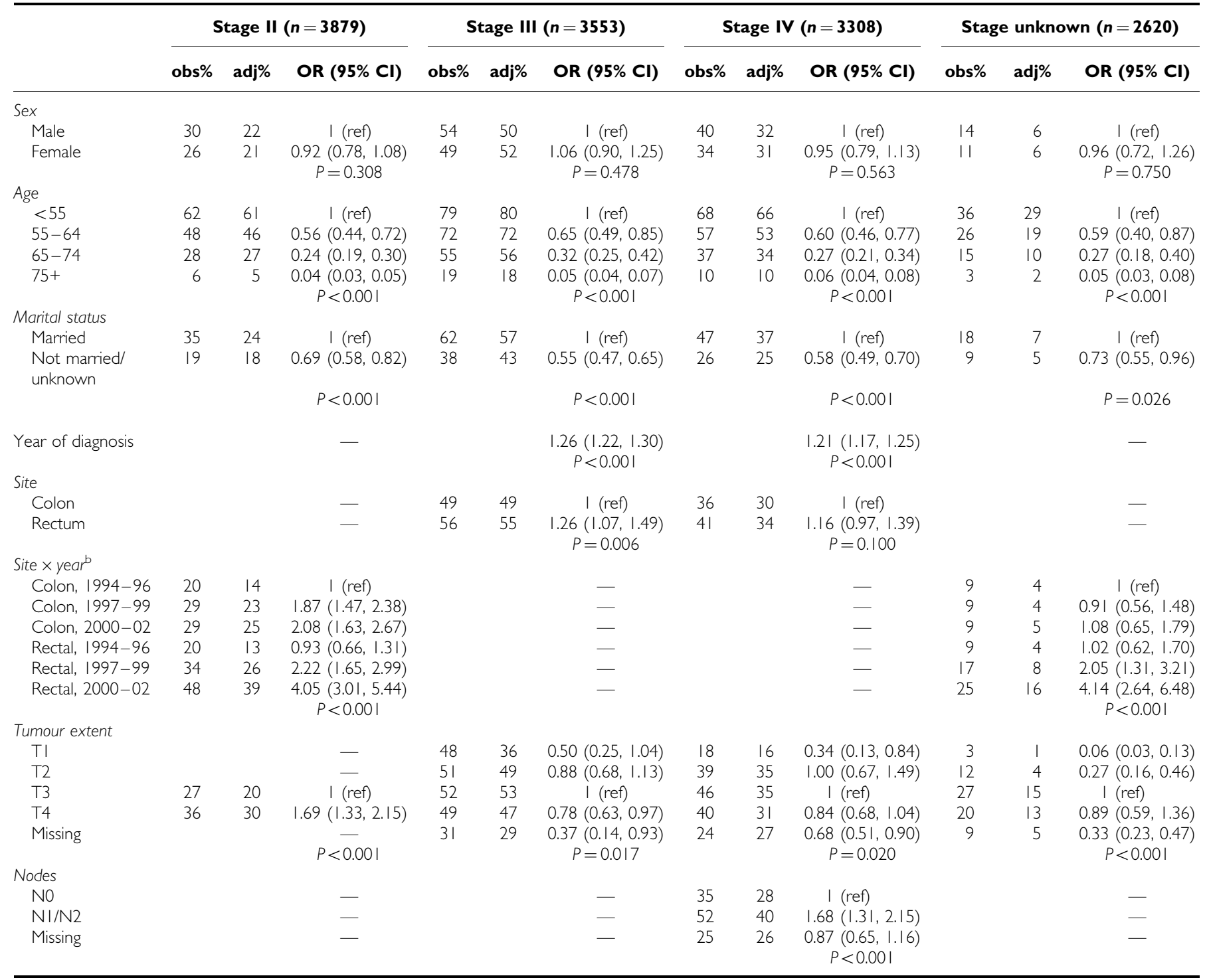

$\mathrm{Cl}=$ confidence interval; $\mathrm{OR}=$ odds ratio. ${ }^{\mathrm{a}}$ Odds ratios adjusted for factors shown in relevant column, plus health board and grade. ${ }^{\mathrm{b}}$ Interaction term for site and period of diagnosis.

cancer, and is one of the few studies conducted outside the USA. We have described treatment patterns in routine clinical practice, rather than in specialized treatment centres, and in a setting with relatively high colorectal cancer mortality (Ferlay et al, 2004). With regard to limitations, we did not have details of specific chemotherapy regimens or radiotherapy courses. However, assessment of such details was not our aim. Although we only had information on treatments received within a year of diagnosis, most active treatment for the primary tumour would be offered within this time. A priori, we could not distinguish whether treatments were given with curative or palliative intent. Stratification of the analysis by stage and investigation of treatment combinations helped clarify this to some extent.

For $40 \%$ of the cases information on $\mathrm{T}, \mathrm{N}$, and $\mathrm{M}$ status was incomplete. The registration procedures of the National Cancer Registry include medical record review, so these data would have been recorded had they been available in notes. In a substantial proportion of these cases, it is probable that the investigations to confirm presence - or more likely absence - of metastases were not carried out. We coded cases with missing metastasis data to no metastasis, reducing the proportion 'unstaged' to $17 \%$. The validity of this assumption was verified by repeating the analyses after assigning patients with missing metastasis data to the unstaged group - our results were not altered.

Other than stage and grade, no prognostic information (e.g. bowel perforation, number of lymph nodes examined, etc.) was available. Such factors are likely to have determined treatment aggressiveness and survival, especially among stage II colon cancer patients, who comprise a particularly heterogeneous group (André et al, 2006).

\section{Treatment rates and trends over time}

The colorectal resection rate was constant over time, in contrast to a US study that reported a slight, but significant, decrease during 1988-2000 (Cook et al, 2005). Our frequency of 78\% undergoing resection was lower than that in US studies (90-92\%; Ciccolallo et al, 2005) but close to figures for European community practice 
Table 3 Factors associated with radiotherapy receipt among rectal cancer patients diagnosed during 1994-2002: observed and adjusted percentages, multivariate $\mathrm{ORs}^{\mathrm{a}}$ with $95 \% \mathrm{Cls}$, and $P$-values

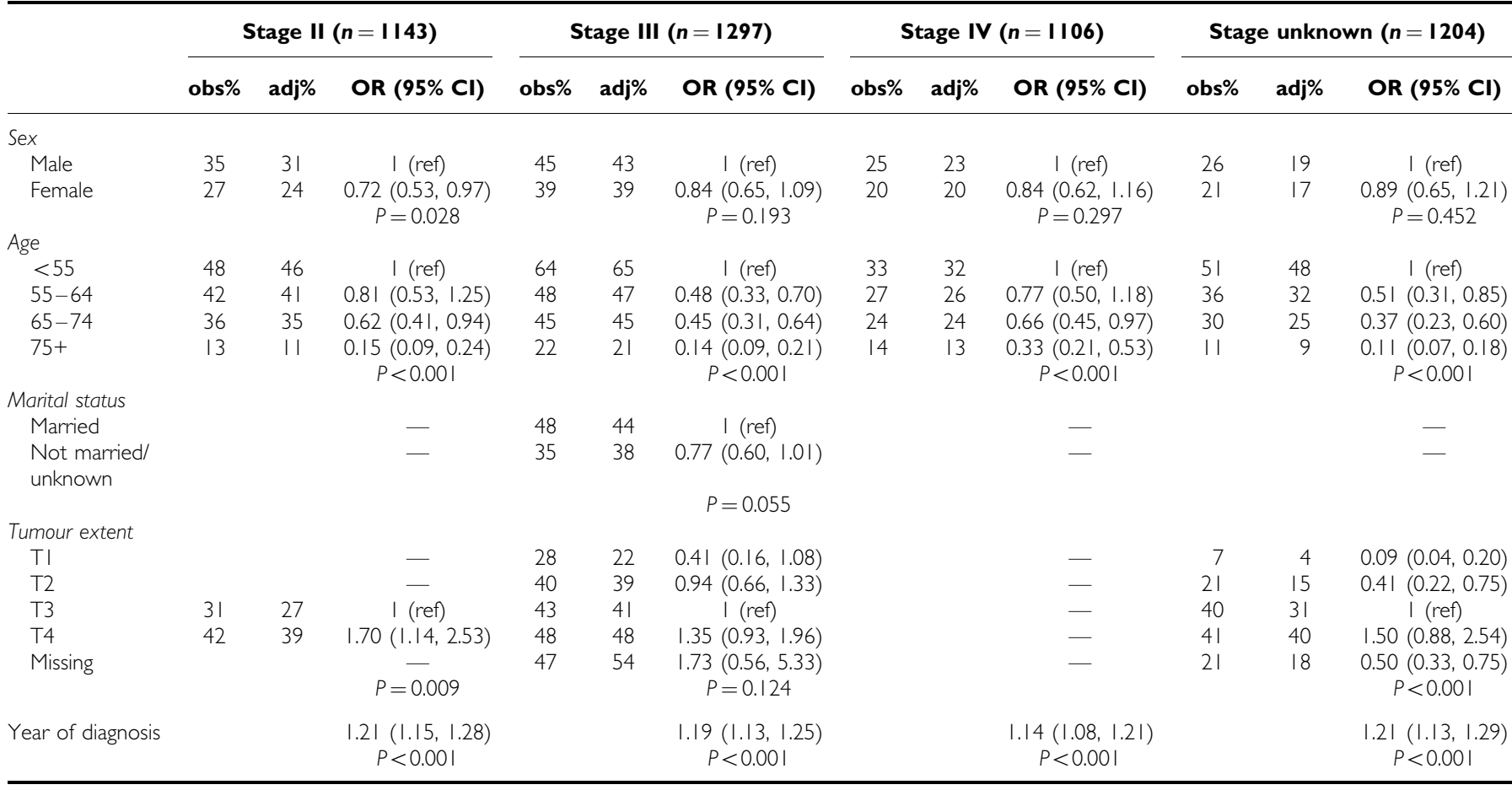

$\mathrm{Cl}=$ confidence interval; $\mathrm{OR}=$ odds ratio. ${ }^{\mathrm{a}} \mathrm{Odds}$ ratios adjusted for factors shown in relevant columns. Stage II, III, and unknown stage disease are also adjusted for health board. Stage IV and unknown stage disease are also adjusted for grade.

(Gatta et al, 2000; Pitchforth et al, 2002). The differences may be partly a result of variations in stage distribution between populations, but are more likely to be due to lack of consensus regarding resection of the primary tumour in stage IV patients (Rosen et al, 2000; Sarela et al, 2001; Ruo et al, 2003). In two US population-based studies, $66 \%$ of stage IV patients of all ages (Cook et al, 2005) and $72 \%$ of those aged $\geqslant 65$ had primary cancerdirected surgery (Temple et al, 2004); this was $51 \%$ in our study overall.

One of the major reasons for examining treatment patterns in routine clinical practice is to determine whether potential exists for further dissemination of therapies across the patient population. The increased use of chemotherapy and radiotherapy over time (10 and $12 \%$ per annum, respectively) suggests some dissemination of RCT-approved therapies into community practice. The dramatic increase in pre-operative radiotherapy for rectal cancer from 2000 onwards is similar to recent US trends (Cronin et al, 2006). It is noteworthy, however, that post-operative radiotherapy is still commonly used in our population, in contrast to the USA and the Netherlands, where there has been a shift to pre-operative administration (Martijn et al, 2003; Cronin et al, 2006). In the Netherlands this was due to implementation of new guidelines, and illustrates the potential for these (which do not exist in Ireland) to influence patient management in routine practice.

Use of chemotherapy was slightly lower in our population than in US community practice (Jessup et al, 2005; Cronin et al, 2006). This was particularly true for older patients: $38 \%$ of stage III patients over 65 in Ireland had chemotherapy compared with 55\% in the United States in 1991-96 (Schrag et al, 2001a). Similarly, only $24 \%$ of over 65 with stage IV disease had chemotherapy compared with $44 \%$ in the United States in 1991-99 (Temple et al, 2004). Somewhat more reassuringly, when compared with other European population-based series from the 1990s, utilization of chemotherapy in our population did not appear to be unusually low (Bouchardy et al, 2001; Faivre-Finn et al, 2002). For rectal cancer, however, radiotherapy use was low compared to both US and European populations (28\% in Ireland vs $46-62 \%$ elsewhere) (Ayanian et al, 2003; Cronin et al, 2006; Vulto et al, 2007). Possible reasons for this include a lack of guidelines, lack of centralisation and specialisation of cancer services during the study period, and a shortfall in radiation oncology services (Expert Working Group on Radiation Oncology Services, 2003).

In our study, $17 \%$ of patients did not receive any cancer-directed treatment. This group comprised mainly elderly patients who presented late and for whom treatment options were likely to be limited. Almost $60 \%$ were 75 or older at diagnosis and a further $27 \%$ were $65-74$ years; $45 \%$ were stage IV and $47 \%$ had unknown stage disease. The median survival of the entire group was only 2 months. Whether this might have been longer had some of these individuals received treatment (e.g. by irinotecan or oxaliplatin with 5-FU; NICE, 2005) is open to speculation.

\section{Factors associated with treatment}

As only $4 \%$ of stage I-III cases did not have surgery, we were unable to investigate factors associated with not undergoing resection for these patients. For stage IV disease, the likelihood of colorectal resection declined with increasing age. This was also observed in two US series (Temple et al, 2004; Cook et al, 2005), although in both series the effect was mainly limited to the very old ( 80 or 85 and over), whereas in our study there was a steady decrease with increasing age (60\% of the under $65 \mathrm{~s}$ had a resection, whereas only $51 \%$ aged $65-74$ and $42 \%$ aged $\geqslant 75$ did). In addition to having more co-morbid conditions (Yancik et al, 1998), older patients are more likely to require emergency surgery (Colorectal Cancer Collaborative Group, 2000a), and these factors may influence the proportion resected in different populations. We also found that female, stage IV patients were significantly more likely to undergo resection, which has not been seen elsewhere. 
Table 4 Factors associated with risk of death among colorectal cancer patients diagnosed during 1994-2002, stratified by receipt of surgery: HRs, ${ }^{a}$ 95\% Cls, and P-values

\begin{tabular}{|c|c|c|}
\hline & $\begin{array}{c}\text { No surgery } \\
(n=3373) \\
\text { HR }(95 \% \mathrm{Cl})\end{array}$ & $\begin{array}{c}\text { Surgery }^{b} \\
(n=11876) \\
\text { HR }(95 \% \mathrm{Cl})\end{array}$ \\
\hline \multicolumn{3}{|l|}{ Sex } \\
\hline Male & 1.00 & 1.00 \\
\hline Female & $\begin{array}{c}0.90(0.84,0.98) \\
P=0.010\end{array}$ & 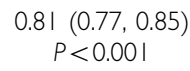 \\
\hline \multicolumn{3}{|c|}{ 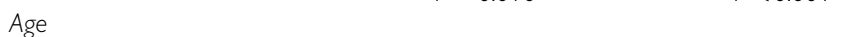 } \\
\hline $\begin{array}{l}<55 \\
55-64\end{array}$ & $\begin{array}{c}1.00 \\
1.10(0.94,1.29)\end{array}$ & $\begin{array}{c}1.00 \\
1.12(1.02,1.23)\end{array}$ \\
\hline $65-74$ & $1.41(1.22,1.63)$ & $1.42(1.30,1.55)$ \\
\hline $75+$ & $\begin{array}{c}1.70(1.47,1.96) \\
P<0.00 \mid\end{array}$ & $\begin{array}{c}2.16(1.97,2.37) \\
\quad P<0.001\end{array}$ \\
\hline \multicolumn{3}{|l|}{ Stage } \\
\hline 1 & $0.48(0.32,0.71)$ & $0.36(0.33,0.40)$ \\
\hline$\|$ & $0.76(0.58,0.98)$ & $0.58(0.54,0.62)$ \\
\hline III & 1.00 & 1.00 \\
\hline IV & $2.31(1.91,2.78)$ & $2.83(2.64,3.03)$ \\
\hline Unknown & $\begin{array}{c}1.33(1.10,1.61) \\
P<0.00 \mid\end{array}$ & $\begin{array}{c}0.69(0.63,0.76) \\
P<0.001\end{array}$ \\
\hline \multicolumn{3}{|l|}{ Marital status } \\
\hline Married & 1.00 & 1.00 \\
\hline Not married/unknown & $\begin{array}{c}1.12(1.04,1.21) \\
P=0.005\end{array}$ & $\begin{array}{c}1.12(1.06,1.18) \\
P<0.001\end{array}$ \\
\hline \multicolumn{3}{|l|}{ Smoking status } \\
\hline Non-smoker/unknown & 1.00 & 1.00 \\
\hline Current smoker & $1.09(1.00,1.20)$ & $1.14(1.07,1.22)$ \\
\hline Ex-smoker & $\begin{array}{c}1.10(0.99,1.22) \\
P=0.06 \mid\end{array}$ & $\begin{array}{c}1.03(0.96,1.10) \\
P<0.001\end{array}$ \\
\hline \multicolumn{3}{|l|}{ Grade } \\
\hline Well & 1.00 & 1.00 \\
\hline Moderate & $0.94(0.79,1.13)$ & $1.06(0.97,1.16)$ \\
\hline Poor/undifferentiated & $1.43(1.17,1.75)$ & $1.40(1.27,1.56)$ \\
\hline Missing & $\begin{array}{c}1.15(0.96,1.36) \\
P<0.001\end{array}$ & $\begin{array}{c}1.12(1.01,1.25) \\
\quad P<0.001\end{array}$ \\
\hline \multicolumn{3}{|l|}{ Period of diagnosis } \\
\hline $1994-96$ & & 1.00 \\
\hline 1997-99 & - & $0.87(0.82,0.92)$ \\
\hline $2000-02$ & & $\begin{array}{c}0.82(0.76,0.87) \\
\quad P<0.001\end{array}$ \\
\hline
\end{tabular}

$\mathrm{Cl}=$ confidence interval; $\mathrm{HR}=$ hazard ratio. ${ }^{\mathrm{a}} \mathrm{All}$ HRs adjusted for factors shown in relevant column (other than site), plus health board and site (colon/rectum). ${ }^{b}$ Models also stratified by receipt of chemotherapy and radiotherapy.
The reason for this is unclear, but co-morbidities may be relevant here also; Yancik et al (1998) found that female patients were less likely than male patients to have a high-impact life-threatening co-morbid condition.

With regard to adjuvant treatment, we observed significant disparities in use even after adjusting for stage and other clinical factors. The increased likelihood of treatment in married patients was also noted in a small chemotherapy study (Bouchardy et al, 2001). The explanation is not clear but possibilities include active involvement of spouse/family members in care management, spousal support (emotional and logistical) during treatment, and different perceptions - by clinicians or patients - of the 'value' of life in those with and without a spouse and/or dependants. Age was the strongest predictor of receipt of chemotherapy or radiotherapy. Although reported elsewhere (Faivre-Finn et al, 2000; Schrag et al, 2001a,b; Cronin et al, 2006), this finding remains important given that one-third of colorectal cancer patients are 75 or older. Although the higher prevalence of co-morbidities (Yancik et al, 1998) may preclude treatment in some elderly patients, in the United States the age effect persists even among those without comorbidities (Schrag et al, 2001a,b). Older patients may also have increased treatment-related toxicity, although evidence on this is mixed (Sargent et al, 2001). Both RCTs (Sargent et al, 2001) and observational studies (Bouchardy et al, 2001; Schrag et al, 2001a; Jessup et al, 2005) demonstrate clear survival benefits of adjuvant chemotherapy in patients of all ages, suggesting that there may be further potential for (and benefits to be gained from) extended use in older patients in routine practice.

Randomised controlled trials suggest that chemotherapy may benefit stage II colon patients with poor prognostic features (Gill et al, 2004; Australian Cancer Network Colorectal Cancer Guidelines Revision Committee, 2005; André et al, 2006). These findings appear to have disseminated into routine practice, as those stage II patients in our study with more extensive tumours were significantly more likely to be treated.

\section{Factors associated with mortality}

Among surgical patients, risks of death decreased over time, which may be partly due to reductions in post-operative mortality (Faivre-Finn et al, 2002). The increased risk of death with increasing age among surgical patients may also be a function of post-operative mortality. In further analyses, patients aged $\geqslant 75$ were four times more likely to die in the

Table 5 Risk of death by adjuvant treatment ${ }^{a}$ for colorectal cancers diagnosed during 1994-2002: HRs with 95\% Cls

\begin{tabular}{|c|c|c|c|c|c|c|c|c|}
\hline & \multicolumn{2}{|c|}{ Stage II } & \multicolumn{2}{|c|}{ Stage III } & \multicolumn{2}{|c|}{ Stage IV } & \multicolumn{2}{|c|}{ Stage unknown } \\
\hline & HR & $95 \% \mathrm{Cl}$ & HR & $95 \% \mathrm{Cl}$ & HR & $95 \% \mathrm{Cl}$ & HR & $95 \% \mathrm{Cl}$ \\
\hline \multicolumn{9}{|l|}{ Chemotherapy: colorectal cancer } \\
\hline All patients ${ }^{\mathrm{b}}$ & 0.88 & $(0.77,1.01)$ & 0.67 & $(0.61,0.75)$ & 0.83 & $(0.76,0.91)$ & 1.23 & $(1.03,1.47)$ \\
\hline Surgical patients ${ }^{c}$ & 0.96 & $(0.84,1.10)$ & 0.69 & $(0.62,0.76)$ & 0.77 & $(0.68,0.88)$ & 1.57 & $(1.23,2.00)$ \\
\hline \multicolumn{9}{|l|}{ Radiotherapy: rectal cancer } \\
\hline Surgical+radiotherapy patients: & 1.03 & $(0.63,1.66)$ & 0.61 & $(0.42,0.91)$ & 0.70 & $(0.40,1.25)$ & 0.60 & $(0.36,1.02)$ \\
\hline
\end{tabular}

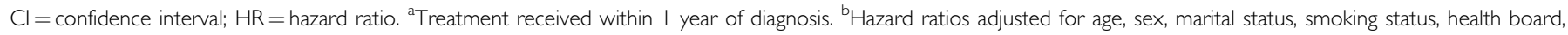

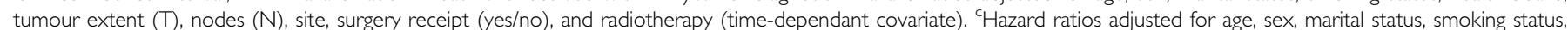

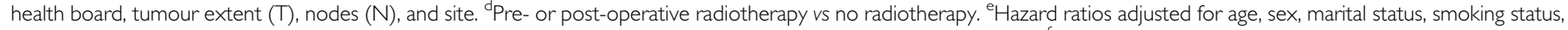

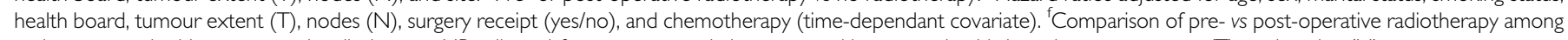
patients treated with surgery and radiotherapy; HR adjusted for age, sex, marital status, smoking status, health board, tumour extent ( $\mathrm{T}$ ), and nodes ( $\mathrm{N}$ ). 


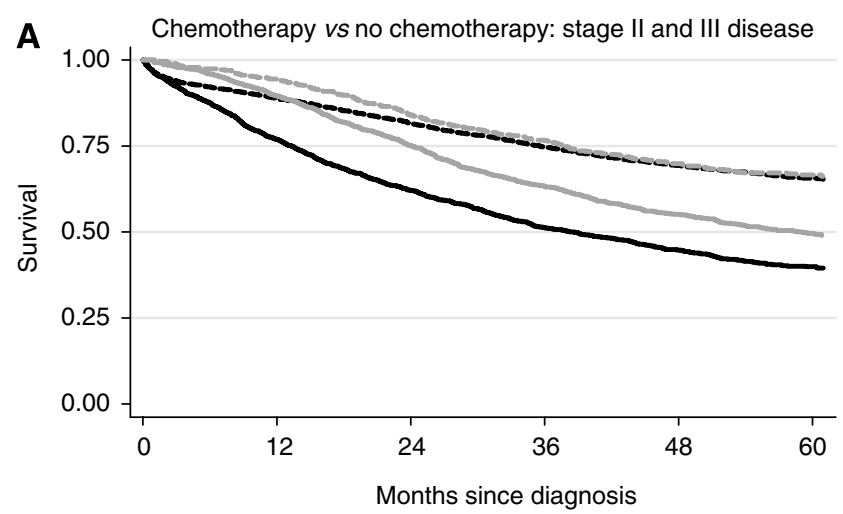

-- Stage II, no chemo Stage III, no chemo
B
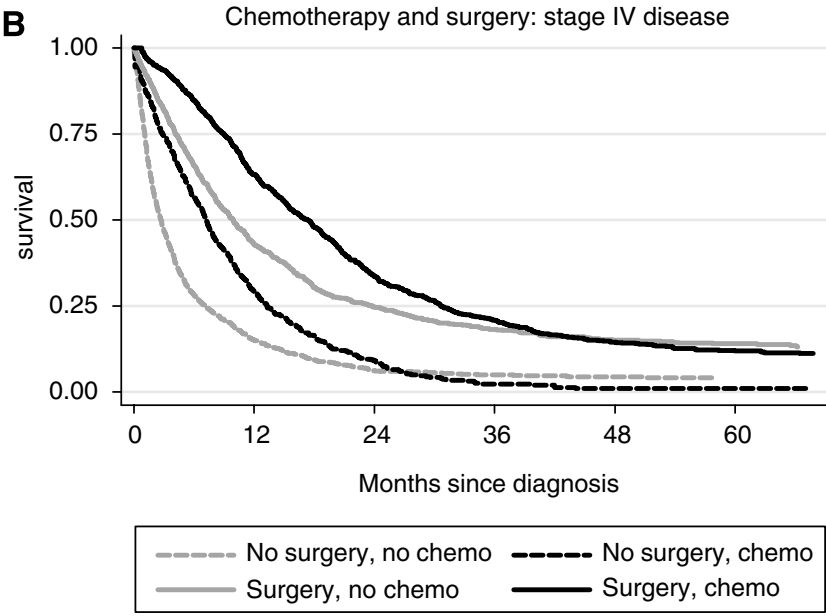

Figure 2 Kaplan-Meier survival curves (adjusted for age) by receipt of treatment: colorectal cancer.

30-day post-operative period than younger patients $(\mathrm{HR}=4.03$, $95 \%$ CI $2.46-6.59$ ).

The increased hazard in those who were smokers at diagnosis is intriguing. As smoking status is based on information recorded in medical records, misclassification is probable, but it is most likely that some smokers would have been categorized as non-smokers rather than the other way; thus, the observed result probably underestimates the true effect. The finding does not seem to be due to deaths from other causes in smokers, as the association persisted when cause-specific mortality was analysed. Two small studies have reported poorer outcomes in smokers following colorectal cancer surgery (Jadallah et al, 1999; Munro et al, 2006). Although the result could be due to confounding by another prognostic factor such as deprivation (Bouchardy et al, 2001; Pitchforth et al, 2002; Wrigley et al, 2003), there are several potential mechanisms by which smoking might adversely affect survival. These include effects on immune function (O'Byrne et al, 2000), inflammatory response (Yanbaeva et al, 2007), metabolism of chemotherapy drugs (van der Bol et al, 2007), and genetic damage and repair capacity (Fracasso et al, 2006).

\section{Treatment, survival, and mortality}

We investigated the impact of treatment on mortality and survival primarily to determine whether the advances seen in RCTs have translated into improvements for the entire patient population. Clearly, survival comparisons in an observational study are potentially subject to bias and will tend to favour treatment (because of the selection of patients with better prognostic features for treatment). Although the introduction of time-varying covariates, and adjustment for other factors, would be expected to attenuate the bias somewhat, we cannot exclude the possibility that our results are influenced by unmeasured confounders. The Kaplan-Meier survival curves may be particularly susceptible in this regard, as they are adjusted for age only.

Given the controversy around resection of the primary tumour in stage IV patients, our observations of lower mortality and longer survival among resected patients at the population-level are noteworthy. In particular, the survival advantage conferred by the combination of chemotherapy and surgery is important and compatible with RCT evidence on prolonged survival for advanced patients treated with palliative chemotherapy (Colorectal Cancer Collaborative Group, 2000b). Similar results have recently been reported in the US population-based studies (Temple et al, 2004;
Cook et al, 2005) and clinical series (Ruo et al, 2003; Konyalian et al, 2007). Given that stage IV disease is not uncommon (it accounted for more than one-fifth of our cases), the role of resection of the primary tumour (in combination with chemotherapy) warrants further investigation. Issues such as impact of treatment on quality of life need to be addressed.

The higher survival and significant mortality reduction for stage III patients receiving chemotherapy at the population level is consistent with evidence of survival benefits for colon cancer from RCTs (André et al, 2004a). The lack of a survival advantage for chemotherapy among stage II patients overall is also compatible with RCT evidence which suggests that the survival improvement, if any, is small (Benson et al, 2004; André and de Gramont, 2004b). As we were not able to clearly distinguish stage II patients with particularly poor prognostic features, we cannot exclude a beneficial effect of treatment at the population level in this subgroup.

Although post-operative radiotherapy has been relatively long established as the standard of care for rectal cancer, we found no clear benefit in terms of survival or mortality at the population level in stage II-III patients. This is consistent with a systematic review of 22 RCTs, which concluded that the impact on survival was marginal (Colorectal Cancer Collaborative Group, 2001). In the current study, risk of death was decreased when radiotherapy was administered pre-operatively although the findings were based on small numbers and were not statistically significant for stage II disease. Although RCTs suggest that preoperative radiotherapy reduces rectal cancer deaths, this appears to be at the cost of increased risk of death from other causes (Colorectal Cancer Collaborative Group, 2001). Our results, based on deaths from all causes, suggest that advantages may outweigh disadvantages at the population level, at least for patients diagnosed with stage III disease.

As has been observed elsewhere (Verdecchia et al, 2007), colorectal cancer survival in Ireland is rising (Walsh and Comber, 2007). As the proportion of early-stage tumours did not increase over time and no screening is in place, it is unlikely that this improvement is due to earlier detection. Instead it may reflect the increased use of (neo-) adjuvant treatment that we have shown here - as well as other treatment-related factors such as advancements in surgical techniques, increased specialization, and so on. Despite the improvement, survival in Ireland remains below US figures and the EU average (Verdecchia et al, 2007). Although these differences are probably due in part to stage (Gatta et al, 2000), the relatively lower rates of cancer-directed treatment that we describe probably play a role. 


\section{CONCLUSIONS}

While recognizing that not all patients are suitable candidates for surgery or (neo-)adjuvant therapy, our findings suggest that there is potential for extended dissemination of therapies in routine clinical practice - both overall and in particular patient subgroups. Improving treatment availability generally, and equity specifically, has the potential to increase survival and ultimately reduce mortality at the population level.

\section{REFERENCES}

AJCC (American Joint Committee on Cancer) (2002) AJCC Cancer Staging Manual, 6th edn. Springer-Verlag: New York

André T, Boni C, Mounedji-Boudiaf L, Navarro M, Tabernero J, Hickish T, Topham C, Zaninelli M, Clingan P, Bridgewater J, Tabah-Fisch I, de Gramont A, Multicenter International Study of Oxaliplatin/ 5-Fluorouracil/Leucovorin in the Adjuvant Treatment of Colon Cancer (MOSAIC) Investigators (2004a) Oxaliplatin, fluorouracil, and leucovorin as adjuvant treatment for colon cancer. $N$ Engl J Med 350: $2343-2351$

André T, de Gramont A, Oncology Multidisciplinary Research Group (2004b) An overview of adjuvant systemic chemotherapy for colon cancer. Clin Colorectal Cancer 4: S22-S28

André T, Sargent D, Tabernero J, O'Connell M, Buyse M, Sobrero A, Misset J, Boni C, de Gramont A (2006) Current issues in adjuvant treatment of stage II colon cancer. Ann Surg Oncol 13: 887-898

Australian Cancer Network Colorectal Cancer Guidelines Revision Committee (2005) Guidelines for the Prevention, Early Detection and Management of Colorectal Cancer, 2nd edn. The Cancer Council Australia and Australian Cancer Network: Sydney

Ayanian J, Zaslavsky A, Fuchs C, Guadagnoli E, Creech C, Cress R, O'Connor L, West D, Allen M, Wolf R, Wright W (2003) Use of adjuvant chemotherapy and radiation therapy for colorectal cancer in a population-based cohort. J Clin Oncol 21: 1293-1300

Benson III AB, Schrag D, Somerfield MR, Cohen AM, Figueredo AT, Flynn PJ, Krzyzanowska MK, Maroun J, McAllister P, Van Cutsem E, Brouwers M, Charette M, Haller DG (2004) American Society of Clinical Oncology recommendations on adjuvant chemotherapy for stage II colon cancer. J Clin Oncol 22: 3408-3419

Bouchardy C, Queneau PE, Fioretta G, Usel M, Zellweger M, Neyroud I, Raymond L, de Wolf C, Sappino AP (2001) Adjuvant chemotherapy for colon carcinoma with positive lymph nodes: use and benefit in routine health care practice. Br J Cancer 85: 1251-1257

Cascinu S, Catalano V, Piga A, Mattioli R, Marcellini M, Pancotti A, Bascioni RTU, Silva RR, Pieroni V, Giorgi F, Catalano G, Cellerino R (2003) The role of levamisole in the adjuvant treatment of stage III colon cancer patients: a randomized trial of 5-fluorouracil and levamisole $v \mathrm{~s}$ 5-fluorouracil alone. Cancer Invest 21: $701-707$

Ciccolallo L, Capocaccia R, Coleman M, Berrino F, Coebergh J, Damhuis R, Faivre J, Martinez-Garcia C, Møller H, Ponz de Leon M, Launoy G, Raverdy N, Williams E, Gatta G (2005) Survival differences between European and US patients with colorectal cancer: role of stage at diagnosis and surgery. Gut 54: $268-273$

Coleman M, Estève J, Damiecki P, Arslan A, Renard H (1993) Trends in Cancer Incidence and Mortality. IARC Scientific Publications No. 121 IARC: Lyon

Colorectal Cancer Collaborative Group (2000a) Surgery for colorectal cancer in elderly patients: a systematic review. Lancet 356: $968-974$

Colorectal Cancer Collaborative Group (2000b) Palliative chemotherapy for advanced colorectal cancer: systematic review and meta-analysis. BMJ 321: $531-535$

Colorectal Cancer Collaborative Group (2001) Adjuvant radiotherapy for rectal cancer: a systematic overview of 8507 patients from 22 randomised trials. Lancet 358: $1291-1304$

Cook A, Single R, McCahill L (2005) Surgical resection of primary tumors in patients who present with stage IV colorectal cancer: an analysis of surveillance, epidemiology, and end results data, 1988-2000. Ann Surg Oncol 12: $637-645$

Cronin D, Harlan L, Potosky A, Clegg L, Stevens J, Mooney M (2006) Patterns of care for adjuvant therapy in a random population-based sample of patients diagnosed with colorectal cancer. Am J Gastroenterol 101: $2308-2318$

\section{ACKNOWLEDGEMENTS}

We are grateful to the tumour registration officers and other staff of the NCR involved in the collection and processing of the data on which this study is based. Information from death certificates was provided by the Central Statistics Office. This study was partially supported by a grant from the Health Research Board, Dublin.
Edwards BK, Brown ML, Wingo PA, Howe HL, Ward E, Ries LA, Schrag D, Jamison PM, Jemal A, Wu XC, Friedman C, Harlan L, Warren J, Anderson RN, Pickle LW (2005) Annual report to the nation on the status of cancer, 1975-2002, featuring population-based trends in cancer treatment. J Natl Cancer Inst 97: 1407-1427

Expert Working Group on Radiation Oncology Services (2003) The Development of Radiation Oncology Services in Ireland. Department of Health \& Children: Dublin

Faivre-Finn C, Benhamiche A, Maingon P, Janoray P, Faivre J (2000) Changes in the practice of adjuvant radiotherapy in resectable rectal cancer within a French well-defined population. Radiother Oncol 57: $137-142$

Faivre-Finn C, Bouvier-Benhamiche A, Phelip J, Manfredi S, Dancourt V, Faivre J (2002) Colon cancer in France: evidence for improvement in management and survival. Gut 51: 60-64

Ferlay J, Bray F, Pisani P, Parkin DM (2004) GLOBOCAN 2002: Cancer Incidence, Mortality and Prevalence Worldwide, Version 2.0. IARC Cancer Base No. 5 IARC Press: Lyon

Fracasso M, Doria D, Franceschetti P, Perbellini L, Romeo L (2006) DNA damage and repair capacity by comet assay in lymphocytes of whitecollar active smokers and passive smokers (non- and ex-smokers) at workplace. Toxicol Lett 167: 131-141

Gatta G, Capocaccia R, Sant M, Bell C, Coebergh J, Damhuis R, Faivre J, Martinez-Garcia C, Pawlega J, Ponz de Leon M, Pottier D, Raverdy N, Williams E, Berrino F (2000) Understanding variations in survival for colorectal cancer in Europe: a EUROCARE high resolution study. Gut 47: $533-538$

Gill S, Loprinzi C, Sargent D, Thomé S, Alberts S, Haller D, Benedetti J, Francini G, Shepherd L, Francois Seitz J, Labianca R, Chen W, Cha S, Heldebrant M, Goldberg R (2004) Pooled analysis of fluorouracil-based adjuvant therapy for stage II and III colon cancer: who benefits and by how much? J Clin Oncol 22: 1797-1806

Jadallah F, McCall J, van Rij A (1999) Recurrence and survival after potentially curative surgery for colorectal cancer. $N Z$ Med $J$ 112: $248-250$

Jessup J, Stewart A, Greene F, Minsky B (2005) Adjuvant chemotherapy for stage III colon cancer: implications of race/ethnicity, age, and differentiation. J Am Med Assoc 294: 2703-2711

Konyalian V, Rosing D, Haukoos J, Dixon M, Sinow R, Bhaheetharan S, Stamos M, Kumar R (2007) The role of primary tumour resection in patients with stage IV colorectal cancer. Colorectal Dis 9: 430-437

Mamounas E, Wieand S, Wolmark N, Bear HD, Atkins JN, Song K, Jones J, Rockette H (1999) Comparative efficacy of adjuvant chemotherapy in patients with Dukes' B vs Dukes' C colon cancer: results from four National Surgical Adjuvant Breast and Bowel Project adjuvant studies (C-01, C-02, C-03, and C-04). J Clin Oncol 17: 1349-1355

Martijn H, Voogd AC, van de Poll-Franse LV, Repelaer van Driel OJ, Rutten HJ, Coebergh JW (2003) Improved survival of patients with rectal cancer since 1980: a population-based study. Eur J Cancer 39: 2073-2079

Munro A, Bentley A, Ackland C, Boyle P (2006) Smoking compromises cause-specific survival in patients with operable colorectal cancer. Clin Oncol (R Coll Radiol) 18: 436-440

NCR (National Cancer Registry) (2001) Cancer in Ireland, 1994 to 1998: Incidence, Mortality, Treatment and Survival, Report of the National Cancer Registry, National Cancer Registry: Cork, Ireland

NICE (National Institute for Health and Clinical Excellence) (2005) Irinotecan, Oxaliplatin and Raltitrexed for the Treatment of Advanced Colorectal Cancer. Technology appraisal no. 93 NICE: London

NCCN (2006a) Colon Cancer Clinical Practice Guidelines in Oncology (Version 1) National Comprehensive Cancer Network Inc. Available at http://www.nccn.org. Accessed 9 August 2007 
NCCN (2006b) Rectal Cancer Clinical Practice Guidelines in Oncology (Version 1) 2006 National Comprehensive Cancer Network Inc. Available at http://www.nccn.org. Accessed 9 August 2007

O'Byrne K, Dalgleish A, Browning M, Steward W, Harris A (2000) The relationship between angiogenesis and the immune response in carcinogenesis and the progression of malignant disease. Eur J Cancer 36: $151-169$

Pitchforth E, Russell E, Van der Pol M (2002) Access to specialist cancer care: is it equitable? Br J Cancer 87: 1221-1226

Potosky AL, Harlan LC, Kaplan RS, Johnson KA, Lynch CF (2002) Age, sex, and racial differences in the use of standard adjuvant therapy for colorectal cancer. J Clin Oncol 20: 1192-1202

Rosen S, Buell J, Yoshida A, Kazsuba S, Hurst R, Michelassi F, Millis J, Posner M (2000) Initial presentation with stage IV colorectal cancer: how aggressive should we be? Arch Surg 135: 530 - 534

Ruo L, Gougoutas C, Paty P, Guillem J, Cohen A, Wong W (2003) Elective bowel resection for incurable stage IV colorectal cancer: prognostic variables for asymptomatic patients. J Am Coll Surg 196: 722-728

Sarela A, Guthrie J, Seymour M, Ride E, Guillou P, O’Riordain D (2001) Non-operative management of the primary tumour in patients with incurable stage IV colorectal cancer. Br I Surg 88: 1352 - 1356

Sargent D, Goldberg R, Jacobson S, Macdonald J, Labianca R, Haller D, Shepherd L, Seitz J, Francini G (2001) A pooled analysis of adjuvant chemotherapy for resected colon cancer in elderly patients. $N$ Engl J Med 345: $1091-1097$

Sauer R, Becker H, Hohenberger W, Rodel C, Wittekind C, Fietkau R, Martus P, Tschmelitsch J, Hager E, Hess CF, Karstens JH, Liersch T, Schmidberger H, Raab R, GRCS Group (2004) Preoperative vs postoperative chemoradiotherapy for rectal cancer. $N$ Engl J Med 351: $1731-1740$

Schrag D, Cramer LD, Bach PB, Begg CB (2001a) Age and adjuvant chemotherapy use after surgery for stage III colon cancer. J Natl Cancer Inst 93: 850-857

Schrag D, Gelfand S, Bach P, Guillem J, Minsky B, Begg C (2001b) Who gets adjuvant treatment for stage II and III rectal cancer? Insight from surveillance, epidemiology, and end results-Medicare. J Clin Oncol 19: $3712-3718$
SIGN (Scottish Intercollegiate Guidelines Network) (2003) Management of Colorectal Cancer A National Clinical Guideline. No. 67 SIGN: Edinburgh

Temple L, Hsieh L, Wong W, Saltz L, Schrag D (2004) Use of surgery among elderly patients with stage IV colorectal cancer. J Clin Oncol 22: 3475-3484

Twelves C, Wong A, Nowacki MP, Abt M, Burris III H, Carrato A, Cassidy J, Cervantes A, Fagerberg J, Georgoulias V, Husseini F, Jodrell D, Koralewski P, Kroning H, Maroun J, Marschner N, McKendrick J, Pawlicki M, Rosso R, Schuller J, Seitz JF, Stabuc B, Tujakowski J, Van Hazel G, Zaluski J, Scheithauer W. (2005) Capecitabine as adjuvant treatment for stage III colon cancer. $N$ Engl J Med 352: 2696-2704

van der Bol J, Mathijssen R, Loos W, Friberg L, van Schaik R, de Jonge M, Planting A, Verweij J, Sparreboom A, de Jong F (2007) Cigarette smoking and irinotecan treatment: pharmacokinetic interaction and effects on neutropenia. J Clin Oncol 25: 2719-2726

Verdecchia A, Francisci S, Brenner H, Gatta G, Micheli A, Mangone L, Kunler I, the EUROCARE-4 Working Group (2007) Recent cancer survival in Europe: a 2000-02 period analysis of EUROCARE-4 data. Lancet Oncol 8: 784-796

Vulto J, Louwman W, Lybeert M, Poortmans P, Rutten H, Brenninkmeijer S, Coebergh J (2007) A population-based study of radiotherapy in a cohort of patients with rectal cancer diagnosed between 1996 and 2000 Eur J Surg Oncol 33: 993 -997

Walsh P, Comber H (2007) Patterns of Care and Survival of Cancer Patients in Ireland 1994-2001: Time-trends and Regional Variation for Breast, Colorectal, Lung and Prostate Cancer. Summary report. National Cancer Registry: Cork

Wrigley H, Roderick P, George S, Smith J, Mullee M, Goddard J (2003) Inequalities in survival from colorectal cancer: a comparison of the impact of deprivation, treatment, and host factors on observed and cause specific survival. J Epidemiol Commun Health 57: $301-309$

Yanbaeva D, Dentener M, Creutzberg E, Wesseling G, Wouters E (2007) Systemic effects of smoking. Chest 131: 1557-1566

Yancik R, Wesley M, Ries L, Havlik R, Long S, Edwards B, Yates J (1998) Comorbidity and age as predictors of risk for early mortality of male and female colon carcinoma patients: a population-based study. Cancer 82: $2123-2134$ 